\title{
Sharing humour digitally in family communication
}

\author{
Anastasiya Fiadotava \\ University of Tartu \\ Estonian Literary Museum, Estonia \\ zhvaleuskaya@gmail.com
}

\begin{abstract}
This paper offers a folkloristic perspective on the features and dynamics of sharing humorous content digitally within a family in the context of daily communication. The data, collected from 60 Belarusian families via oral interviews and an online survey (175 respondents), were subjected to quantitative and qualitative content and context analysis. The results suggest that sharing humour digitally within a family can take various forms, some of which parallel oral face-to-face interactions, while others complement them. The most preferable ways of sharing are those that ensure the privacy of conversation, thus providing family members with an opportunity to follow the customary patterns of communication while adapting them to the new spatiotemporal circumstances. Even though the process of selecting humorous content to share with one's family does not necessarily involve conscious reflection on the sharer's part, some tendencies clearly transpire from the data. For example, visual and generic forms of humour are more popular than textual and personal ones. Sharing such humour presupposes certain considerations about its recipients, thus making the fact that one's audience is their family an important consideration in the practice of digital sharing.
\end{abstract}

Keywords: humour, online, sharing, family, Belarus.

\section{Introduction}

Sharing humour digitally is one of the most popular forms of humorous communication in contemporary society (Shifman 2007) and as such it penetrates even into spheres of life that are characterised by high reliance on face-to-face communication, such as the family. While face-to-face oral humorous interactions ${ }^{1}$ continue to play an important role in family communication (Fiadotava forthcoming), the increasing presence of technology-mediated communication between family members also warrants further exploration. This is because this newer form of communication opens up new perspectives for creative engagement with

\footnotetext{
${ }^{1}$ By humorous interactions I mean particular communicative events that happen within the broader area of family communication. While many of them are unintentional, the focus of this paper is on intentional sharing of digital humour.
} 
humorous content and its genres, as well as opportunities for family interactions in various spatial and temporal circumstances.

The aim of this paper is to analyse the specific features and dynamics of sharing humour digitally within a family in the context of daily communication. Why do some people prefer sharing humour digitally rather than orally? How do people reflect on the content of the humour that they share digitally with their family members? What genres of humour are shared most often? What are the hybrid forms of sharing humour that exist on the border between digital and oral humour transmission? What makes digital sharing within the family special? These questions suggest that family humorous communication is a continuum between digital and analogue realms, rather than these being two separate modes of sharing humour (Blank 2012: 7).

In this paper I will understand digital sharing of humour as a broad domain that covers any technologically-mediated humorous communication within a family, even if technology is not central to transmitting the humorous message (for example, one of the family members uses it to find humorous content which they subsequently retell to the other family members orally). In most cases, digital sharing equals online sharing, although it also incorporates other considerably less popular technologies, such as, for example, the short message service (SMS). Digital sharing can also incorporate a broader spectrum of communicative phenomena (for instance, joke-telling or conversational humour during voice and video calls via Skype/Viber and similar apps); however, in the present paper I will focus on the instances when family members share humour in the message form and will not analyse oral conversations taking place on VoIP (Voice over Internet Protocol) and video conferencing applications.

Digitally shared humour is also diverse in its content. Some of the content can be personal and idiosyncratic, while other instances can be generic and easily understood across different families and even across different cultures. Certain genres of humour (such as memes, YouTube videos or GIF animations) are specific to digital communication; others can be transmitted both orally and digitally (cf. Boxman-Shabtai \& Shifman 2015). By discussing the preference towards particular genres and topics of humour, I intend to uncover the processes of selection that lie behind the digital sharing. While the emphasis is on the family context, I will also touch upon some broader social implications of sharing humour digitally, such as, for example, age-related issues in digital communication.

While my initial intention was to focus on nuclear families, during the course of my research I realised that in many cases it is impossible to single out nuclear families in the context of humorous communication. Therefore, in order to outline a broader perspective on family humour, it turned out to be more productive to rely on emic definitions of family (cf. Tillman \& Nam 2008), which for my research participants often included not only members of their nuclear families, but also their extended families, especially if they lived together with them or maintained close contact. It was mostly the younger families who have not been married for a long time by the time of the interview who referred to their parents, adult siblings and in-laws, but some of the older respondents tended to incorporate members of their extended families into the discussion of family humour as well. The ways people define a family are closely connected to their conceptualisation of family communication (Edwards \& Graham 2009). The distinctness of the latter concept is based on the premise that "the family embodies a rich and distinct set of expectations or relevancies" (Koerner \& Fitzpatrick 2002: 72). Taking all these factors into consideration, I relied on methods that allowed me to contextualise my data. 


\section{Methodology and data}

The present paper is a result of a case study of Belarusian families; however, due to globalisation in terms of both the content and the patterns of digital communication, I believe that the observations and conclusions contained in this paper can also apply beyond this immediate ethnic and geographic focus. The data for this paper come from two independent fieldwork projects. The first set of data comes from 60 oral semi-structured interviews, which I conducted with Belarusian couples aged between 24 and 66 in 2016-2017. Most of the couples that I interviewed lived in Minsk, but there were also couples from Brest, Mogilev, Slutsk and Maryina Horka, and two of the couples resided outside of Belarus at the time of the interview. As my initial idea was to focus on dyadic traditions (Oring 1984), I tended to schedule interviews with both spouses only, but in some cases (when the interviews took place at my interviewees' homes) their children were also present and took an active part in them. The interviews were conducted either face-to-face or via Skype/Viber; in rare cases involving older couples from outside of Minsk, I talked to my interviewees over telephone. The interviews were conducted either in Russian or in Belarusian (depending on the language that my interviewees preferred), with excerpts of these interviews later translated into English by me.

The interviews covered a broad range of questions relating to family humorous folklore; most of the questions focused on "offline" forms of humour, such as teasing, telling and making jokes, using humorous nicknames and maintaining funny family traditions. The initial questionnaire that I used for my research did not in fact include any questions about digital sharing. However, as the fieldwork continued, I noticed that my interviewees recurrently mentioned sharing humour digitally with their partners or other family members. In many cases digital sharing was evoked in contrast to telling canned jokes orally (especially by the interviewees in their $20 \mathrm{~s}$ and $30 \mathrm{~s}$ ), but there were also instances when digital sharing was framed as complementary to oral joke-telling. This piqued my interest, and I included a question about it in the questionnaire. Although many people readily acknowledged sharing humour digitally, it was not easy for most of them to come up with specific examples during the oral interview, since it was often challenging to translate humour from digital into oral form (on the mediation between digital and analogue popular culture, see Andrews 2019), or even recall digital instances of humour in the first place.

At that point I realised that studying digital humour should also involve digital fieldwork. Thus, in 2019 I conducted the second part of my fieldwork using an online survey that included such questions as "Do you or your family members tell each other jokes?", "Do you share funny texts/images/videos etc. online?", "With whom of your family members do you usually share funny texts/images/videos etc. online?", "Under what circumstances do you share funny texts/images/videos etc. with your family members?", "What forms of humour do you usually share within the family?", "How do you usually share funny texts/images/videos etc.?" The survey also invited participants to upload or send a link to examples of humour they had recently shared within their family, and to reflect on why that humorous example was shared and whether it was in any way relevant to their family relations. 175 respondents (126 female, 48 male, and one participant who chose not to disclose their gender; aged 18 to 58) participated in the survey. The respondents shared a total of 47 videos/animations, $134^{2}$ images (86 of them were image macros, 32 were images without captions, and 16 were personal photos) and 77 textual jokes or other textual genres of humour, along with several links to humorous blogs, forum threads and a humorous test. Some of the survey participants

\footnotetext{
${ }^{2}$ Including 4 images that were sent to me twice and 1 image that was sent to me twice, but with different captions.
} 
had been among my interviewees during the first phase of the fieldwork, but the participant pool also included other people, enrolled through snowball sampling.

This approach to data collection has its strengths and its limitations. On the positive side, the examples in my corpus are accompanied by commentaries and reflections of those who shared them regarding why they decided to use them in their family communication. However, by submitting the examples (even via an anonymous survey) my respondents were aware of the fact that these examples would be used during an academic research. This might account for a degree of self-censorship: some examples might be too intimate to share with a researcher, and some might be deemed inappropriate (for instance, a very small proportion of the examples I received contains obscene language and slang words).

In the present paper I will analyse the data collected during these two phases of fieldwork from a folkloristic perspective. While I will touch on the quantitative data from the survey, my main focus will be on the qualitative data resulting from the interviews, openended questions in the survey, and the examples of humour shared by respondents. The main method of the qualitative interpretation used in this paper is content analysis of the humorous data; however, it is also supplemented with the analysis of the context in which these examples were shared with family members.

An important terminological issue arises when we discuss humour and online communication. In the present paper I discuss the digital sharing of various genres of humour, which includes not only established and publicly accessible genres such as Internet memes, humorous videos and so on (which I will refer to as generic forms of folklore), but also personal media genres (Lüders 2010), for example, homemade videos and photos. As I did not focus exclusively on the genres of humour that are specific to online communication, some examples in my sample can be (and in fact are) shared both digitally and orally among family members.

\section{Practices and ways of sharing humour digitally}

As of 2018, almost 80 per cent of the population of Belarus used the Internet, and the vast majority of Internet users aged 10+ used the Internet for communicative purposes (Medvedeva et al. 2019: 71). One of the widespread means of communication are social media and messenger apps, Viber being the most popular with a 70 per cent market share (E-Belarus.org, 2019), followed by Skype, WhatsApp, Telegram, and Facebook Messenger. The high prevalence of Internet communication makes it possible to assume that some of this communication is humorous and take a closer look at the patterns of such interactions.

One of my survey questions asked the participants to estimate how often they share humour digitally within their family. It should be noted that, since survey participants were mostly enrolled via social media and email, all of them engage in online communication at least to some extent ${ }^{3}$. 21.1 per cent of my respondents reported sharing humorous content digitally every day; 41.7 per cent did it several times a week; and 21.7 per cent did it several times a month. Others shared humour digitally with their family members less frequently, and around 9.7 per cent reported not doing it all. Most representatives of the latter group, however, did say they shared humour digitally with their friends; only 3 respondents claimed that they did not share humour digitally either with friends or family members. In the comments section, some of the respondents who shared humour digitally with their friends rather than within the family explained that their humorous communication with friends was more informal than with family members. Importantly, a lack of digital sharing does not indicate a

\footnotetext{
${ }^{3}$ In contrast to some of the people whom I interviewed orally.
} 
general absence of humour in the family: the vast majority of those who do not share humour with their family digitally still do it by telling personal and/or canned jokes orally.

These data indicate that sharing humour digitally with family members is a fairly common and recurrent part of online communication, although its frequency can vary. If we compare sharing humour digitally with oral joke-telling ${ }^{4}$, we can see that the latter is slightly more prevalent, but the frequency distribution between different respondents remains similar: 34.9 per cent of my survey respondents claimed to tell jokes orally every day, 39.4 per cent reported doing it several times a week, and a further 14.9 per cent said they did it several times a month.

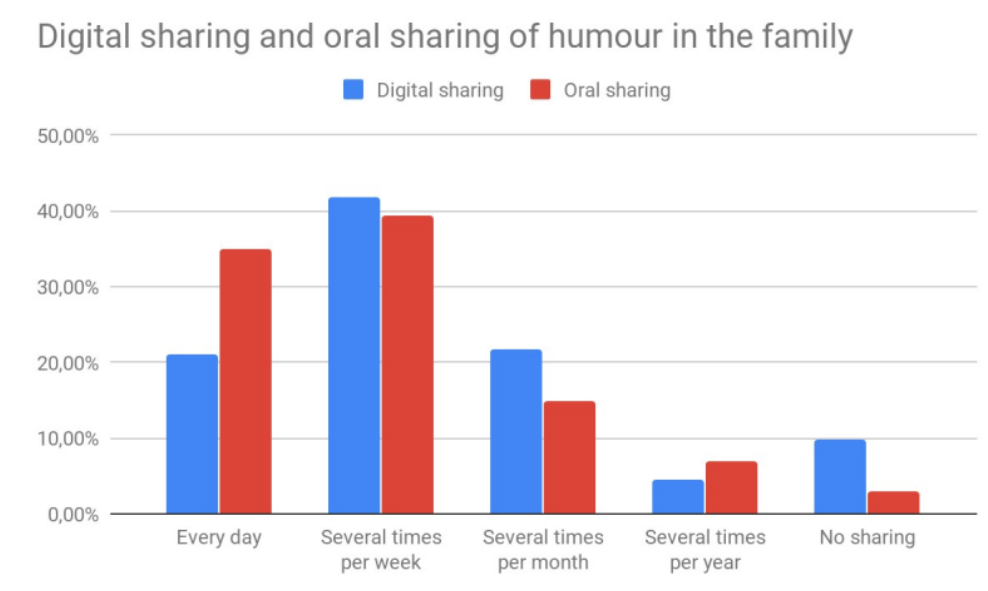

Figure 1. Digital sharing and oral sharing of humour in the family comparison

However, there are also notable distinctions between the practices of oral and digital sharing of humour. One of the key distinctions lies in the performative aspect. The performance of humour, especially in the case of canned jokes, requires certain skills from the performer (Norrick 2003: 1344); conversely, the appreciation of humour also depends on its performance. The repertoire of performative devices is much more limited in digital sharing than in the case of oral face-to-face communication. In the latter context, one can use voice modulations, facial expressions and gestures, as well as other contextualisation cues (see, for example, Tsakona et al. 2010). Digital sharing of humour in the message form is nearly devoid of the performative aspect: one can, of course, add a textual build-up or frame the humorousness using emoticons, but the performativity here is still less apparent than in faceto-face interaction. This means that in digital communication, the content of humour has to be self-contained and not rely so much on the performative aspects.

There are also differences on the spatiotemporal level. While telling jokes in oral humorous communication often requires a certain frame (Norrick 1993: 36), digital communication is not always as immediate as oral, meaning that sharing humour digitally does not necessarily presuppose a build-up. When asked about the circumstances under which they share humour, the respondents mostly reported sending and receiving humorous content when they are away from their family members temporarily during the day ( 77.7 per cent) and/or when they are away from each other for a long time, for example, on long trips (20.6 per cent). Many participants (30.3 per cent), however, also reported sharing humour digitally when they are at home together. Many of my interviewees and respondents mentioned that they shared funny pictures, videos, and so on with each other whenever they found them

\footnotetext{
${ }^{4}$ The data on oral joke sharing also comes from the online survey.
} 
online or created them (in case of personal photos, videos or verbal humour), regardless of where their interlocutors were and what they were doing at that moment. This reflects the broader nature of web browsing and online communication, particularly on social media. Web users are faced with a great amount of information, but it is often very ephemeral and if one does not engage with it immediately, they might not be able to trace it back anymore; the economy of our finite attention ultimately determines the popularity of some internet memes over the others (Weng et al. 2012).

Moreover, digital sharing involves a different temporal pattern of communication. Unlike sharing jokes in oral communication, digital sharing of humour is asynchronous ${ }^{5}$, and as such it does not imply that all the participants are engaged in the conversation at the same time. Consequently, if two or more family members are together at home, but they are not engaged in a common activity, sharing humour digitally can be preferred over oral sharing so that the receiver(s) would not have to react immediately. Such asynchronous nature of online communication reduces the pressure to respond instantly, which is implicitly present in offline communication (McKenna et al. 2002: 19); and in case of humorous communication there may be additional pressure stemming from a perceived need to come up with a humorous reply or a funny example of one's own. However, the recipient's response to digitally shared humour is still important, as illustrated in one of my interviewees' comment:

When I am at home, for me communication is very important, I can send him [the husband] a message while he is making breakfast, and I am writing something to him. Again, I made him install Viber [on his phone], and he gets a message on Viber, and I say: "So how do you like it?". And such sharing is very essential for me. (female, 25 years old)

A key factor behind the popularity of sharing humour digitally within the family is that some genres of humour are too specific to digital communication and cannot be transmitted orally even if the family members are together and have an opportunity to engage in humour at the same time. Some visual-verbal jokes (for example, many image macro memes) can still retain their funniness even when they are retold orally as their humorousness lies on the textual level (Dynel 2016), while others rely on the combination of verbal and visual stimuli to produce a humorous effect.

One way to breach this gap between technologically-mediated communication and the more immediate oral communication is to retell the content of a humorous message (if it can be retained in verbal form) or, alternatively, to show the humorous content on the screen of one's phone, laptop, or tablet rather than send it. This way of sharing humorous content was used by 41.1 per cent of the survey respondents, as well as mentioned by some of my interviewees. Another possible interaction between the oral and digital sharing of humour within the family is the appropriation of Internet-based humour in oral communication. While some interviewees and survey participants mentioned that they just retold the plots of Internet jokes or other genres of digital folklore (in the same way as they would tell any oral joke), others incorporated Internet humour into their offline communication more systematically. For example, one of the survey respondents (male, 27 years old) commented on it thus:

In face-to-face communication, jokes are often based on the same memes or funny videos that we have been sharing [with my partner] throughout the day when we were away from each other.

While many interviewees and survey respondents in their twenties and early thirties both employed sharing humour via messengers/social media and engaged in it in face-to-face communication by using intertextual humour (Gerhardt 2009: 90-96), older interviewees

\footnotetext{
${ }^{5}$ For a brief overview of asynchronous forms of digital communication, see Marchant (2007: 123-124).
} 
tended to prefer the latter option. Some of them articulated this generational issue in their replies:

Wife (46 years old): [My husband] can read something out loud [from the Internet], but it's not regular. Whatever he comes across, sometimes a video, sometimes a phrase. Sending, we don't have it.

Husband (47 years old): We are old school.

Female (34 years old): I personally don't do it [sharing humour digitally], when my friends visit me, I can remember what I have seen, find and show it. Sharing, no, in this respect I do not really keep up with the times, do not really use and post anything on social networks.

Several people of an older age among my interviewees claimed that they did not share Internet humour at all, not even by showing it or reading/retelling it. While some of them do not use the Internet, others mentioned that they used it exclusively for work and not for entertainment. In the open-ended comment to the survey (which, unlike the interviews, focused almost exclusively on the digital sharing of humour), one of the respondents (female, 47 years old) noted:

It seems that you assume that there are no people who do not send anything to anybody, but still value and like humour. ... I have had an acute feeling of inferiority: the life with online humour is somewhere very close, but it passes me by, and I am still trying to please my family members with "face-to-face humorous interaction":)

Age-related issues in the digital sharing of humour are also partly reflected in family members choices' over who to share humour digitally with. Digital sharing of humour is most prominent between partners or spouses: 64.6 per cent of respondents reported that they send and receive humorous content to their husbands/wives or partners. Siblings are also among the popular targets of digital humorous interaction ( 24.6 per cent) followed by parents (23.4 per cent) and children (20 per cent). Other family members feature less frequently in my respondents' replies. Sharing humour within a generation is thus more popular than sharing it across the generation gap. However, the data also indicate that members of the nuclear family who interact with each other offline on a regular basis tend to share humour digitally more often than members of extended families who do not typically enjoy regular personal communication. The frequency of family members' online interactions correlated with the frequency of the offline interactions already back at the time when email was the predominant mode of online communication (Chen et al. 2002: 95). Thus, digital sharing is not a means to fill in the gaps that exist in the offline interaction, but rather an alternative and complementary way to reinforce relationships that are also regularly maintained in an offline form (cf. with text messaging during the previous decades, see Pettigrew 2009).

The sphere of family communication, especially within a nuclear family, is a private one. Digital sharing of humour also adheres to this tendency. The private nature of digital sharing becomes evident when we consider the means that are used to share humour digitally. The survey showed that most people prefer to share humorous content privately via instant messenger apps such as Viber, Skype and WhatsApp (81.1 per cent of the respondents use this option) and via private messages on popular social media platforms (Facebook, Vkontakte and other similar platforms). As mentioned above, 41.1 per cent of the interviewees also show their family members humorous content on the screen of their smartphone, laptop or other electronic device. Only 8.6 per cent reported using public reposts on social media to share humour with their family. Email and SMS were rarely mentioned as ways to transmit humour within the family. 
A close look at the practices of sharing humour digitally within a family reveals that it follows the patterns of sharing humour in offline communication in many ways: it occurs with a similar frequency (see Figure 1), it is closely connected to managing and maintaining relations (Fiadotava forthcoming), nuclear families tend to share humour more often than extended ones, and it happens considerably more often in private than in public. Moreover, digital sharing of humour penetrates into the "analogue" sharing in a variety of ways, thus it is not always possible to separate one from the other (Laineste and Voolaid 2016: 27). Reich et al. argued that teenagers prefer to communicate online with the same people that they have offline relations, thus using digital media to strengthen this offline connection (2012); the same is true for many adults who participated in my research.

Nevertheless, digital sharing is also distinct in several important aspects. One of these is the temporal dimension, which may involve a time gap between units of communication, thus stretching the boundaries of the concept of "sharing a laugh." However, the most important distinction lies in the content of humour that family members tend to share with each other. This aspect will be the main focus of the next section.

\section{The choice of content}

One of the aims of the survey and the interviews was to find out what kind of humour people prefer to share digitally with their family members. The most popular genre of humour to be shared within the family turned out to be images found on the web (83.4 per cent of the respondents chose this option). Videos and verbal jokes (including canned jokes) came second (45.1 per cent indicated that they send videos and 44 per cent chose textual jokes) followed by image macro memes ${ }^{6}$ (39.4 per cent) and personal photos ( 35.4 per cent). GIF animations (29.1 per cent) and personal video clips (14.9 per cent) tended to be somewhat less frequent. Several respondents also mentioned humorous articles and personal jokes as genres of humour they are most likely to share.

As the quantitative data indicate, visual humour, especially in the form of popular images that can be found online, was by far the most popular form of humorous content shared digitally. It was also the most frequent form of humour in the examples that the survey participants included in their survey replies, and it was most recurrently mentioned during the oral interviews. This format is indeed very handy for sharing: there are a lot of humorous images available online, one does not have to spend much time to appreciate them and it is fast and easy to send them via social media, instant messenger apps and other means of digital communication. Other popular formats that are shared with family members also belong to generic Internet humour (as opposed to personal photos and videos). The reason for that may lie in the fact that the latter are much more difficult and time-consuming to produce and might require certain technical skills. Moreover, humour generation is a complex phenomenon on its own and it is not always easy to come up with a verbal or audio(visual) joke that would fit into the format of online communication, which is devoid of many contextual markers integral to oral communication (Kibby 2005: 772).

On the other hand, personal stories, photos and videos are generally more relatable to family members. Some of them might be genuinely incongruent and funny even outside of the family context. For example, one of the survey respondents (female, 28 years old) shared a humorous video of her new pet fish and her two-year old son. The parents pointed the camera at the fish and introduced it as a new member of their household, and then turned to the son and asked what he would call the fish. Even though the son was faced with this question for

\footnotetext{
${ }^{6}$ As image macro memes constitute a particularly popular Internet humour genre (Dynel, 2016), I singled it out in a separate category, though it is overlapping with a more general category of images.
} 
the first time, he replied without hesitation: Zhopa! ("ass" in Russian). The parents were shocked but the incongruity of this reply evoked laughter. Other examples, however, would only be funny for the family members who are aware of the context. A male respondent (29 years old) sent me photos of him and his partner that were transformed into child-like faces using SnapChat app. He commented that they sent these photos to his and his partners' parents. The absurdity (and thus the funniness) of these images was obvious only to the people who knew what they really looked like in their childhood.

In contrast to personal humorous content, generic forms of folklore are not inherently relatable to family members with whom they are shared. During their online activities, people see multitudes of funny images, videos, GIF animations and jokes, but only a fraction of them makes it to the family Viber/Skype/WhatsApp group or personal messages. The criteria for picking up some of the humorous examples and leaving out others may vary, but in many cases the selection process is unconscious. When asked why they sent or received a particular example of humour and whether it had a specific connection to their family, many of my survey participants preferred not to verbalise their reasoning and just said that they found it funny. A possible reason for such reluctance to explain the meaning of humour in a serious manner (as implied by a research survey) lies in the fact that this would make the joke "conform to the requirements of an alien mode of discourse" (Mulkay 1988: 29) and thus ruin it.

Others, however, were more explicit about their choice to share particular examples. The reasons lie on several levels. Firstly, humorous content may be connected to a topic that is generally relevant/interesting to family members. One of such topics is politics. For example, a survey participant (female, 34 years old) included a link to political blog posts (which also include political caricatures) in her survey, and added a comment that both she and her husband are interested in politics and thus share such links.

Some jokes are shared not because family members are particularly interested in their topic, but because they have a shared taste for certain humour style (see Kuipers 2006 for the discussion of tastes in humour). For example, a survey participant (male, 27 years old) shared the following image and commented that he and his partner enjoyed jokes that are based on word play:

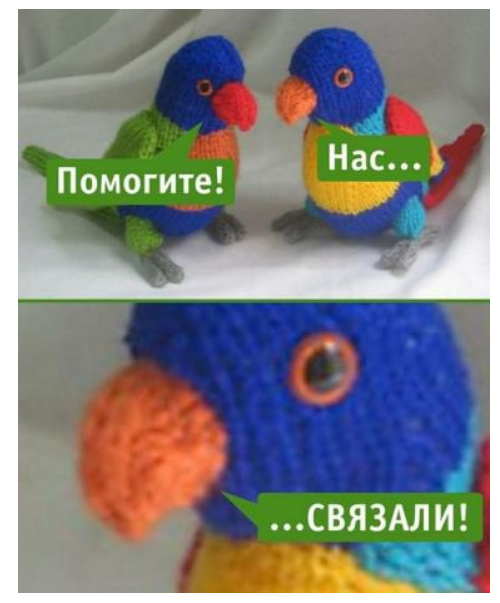

Figure 2. Image macro based on the word play. Captions read: "Help! We are... tied!?"

Families often engage in language play in their daily interactions (Nwokah et al. 2012). However, unlike humour in oral communication, sharing humour based on word play digitally

\footnotetext{
${ }^{7}$ In Russian the word связали (svyazali) means both "tied" and "knitted."
} 
does not usually involve idiosyncratic words and expressions (for a discussion on how such words and phrases can function in oral family humour, see Nevat-Gal 2002: 202-203). This is conditioned by the nature of the content that is shared digitally: as indicated above, most of my respondents preferred generic images found on the web, which leaves little room for improvisation and adapting the content to their specific family idiolect.

Another reason to share a particular example of humorous content lies in the resemblance of joke/meme/video characters to some family members or situations that involve them. In the same way that iconicity correlates with funniness on the level of individual words (see Dingemanse and Thompson 2019), similarities between joke characters or topics and reallife family members and their experiences can also trigger humour. For example, a female survey participant aged 23 shared the following joke:

A maniac is active in the city. He is nicknamed "Barista" because he robs and kills people, and sprinkles coffee on their bodies. Alice is his seventh victim. But he doesn't rob her, because every seventh one is for free.

The survey participant reported sharing this joke with her brother who works as a barista. She commented that the fact that the joke features a "barista" adds an extra layer of funniness both for her and (presumably) for her brother. In a similar vein, if the name of the funny character matches or resembles the name of a family member, the humorous content might be shared with them even if the content of the joke is not otherwise relevant to them.

Finally, some of the interviewees and survey participants pointed out that they share humorous content because they want to share the underlying message of the joke. The most obvious cases are when the humour revolves around family relations. For example, one of my interviewees (female, 25 years old) mentioned digitally sharing her favourite joke with her husband: "Wife [to her husband]: Don't you still understand what marriage is? My money is my money, your money is also my money." She commented that this is especially relevant to her family because her husband earns much more than she does. Humour can also refer to the movies a family watches or other activities they engage in together. If family members work in the same field, professional jokes, shared both orally and digitally, can also become a part of their family folklore.

The degree of correspondence between events and activities in people's lives and in humorous folklore they share may vary. The following image was uploaded to the survey twice by different participants, but the explanations for why it was shared with family members were different:

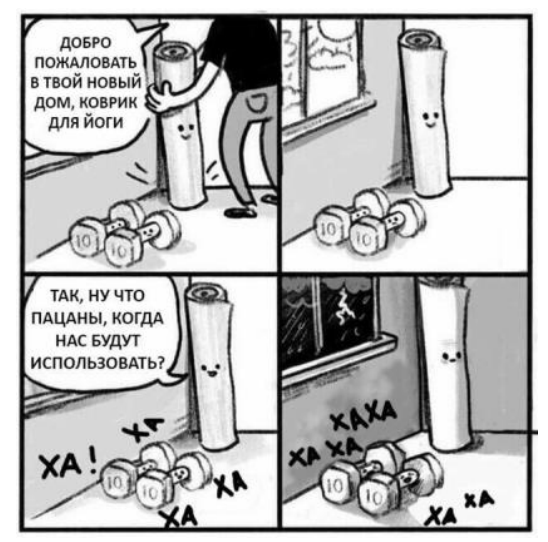

Figure 3. Image macro that inspired different explanations. Captions read: "Welcome to your new home, yoga mat." "So, guys, when will they be using us?" "Ha, ha, ha, ha!"” 
The first survey participant who shared it (male, 26 years old) explained that it had a very direct connection to his life, as he owned dumbbells and had recently bought a yoga mat, but it seemed unlikely that he would do yoga without his sister who was a yoga teacher (and with whom the picture was shared). A 28 -year-old female respondent who uploaded the same image, which she had shared with her husband, described its link to their family in more general terms, namely, that they constantly planned to adopt a more active lifestyle by doing some kind of sports, but always failed to actually do it. These two cases illustrate that different aspects of a humorous folklore item may resonate with different families, and the reception of these items within the family differs accordingly.

That being said, much of the humorous content is shared to communicate a general observation on social reality that may not have a direct connection with the sharer's particular family. The message that people want to convey by sharing humorous folklore is not necessarily humorous; the main idea behind such sharing is to construct shared values with the help of the contemporary genres of folklore (Shifman 2014: 14). For example, a survey participant (female, 42 years old) included a link to a video ${ }^{8}$ that she shared with her child. The video featured the Venezuelan cross-country skier Adrián Solano competing in Ski Championships in Lahti, Finland, in 2017. The inexperienced skier struggles through the race, falling multiple times, breaking his pole and seeking help from coaches. Although dubbed "world's worst skier" by some commentators (Williams 2017), he got a sympathetic reaction from many people from all over the world, my survey participant included. This is how she explained why she shared the video:

This is an example of selfless determination in spite of everything. Don't look up to anyone, pursue your goal ${ }^{9}$

Sometimes people also engage with humorous content on a meta-level. A male survey participant aged 21 shared a link to a blog post where the author cited various historical and geographic "evidence" to prove the nonexistence of the Ukrainian city of Lugansk ${ }^{10}$. The survey participant mentioned that, although this example of humorous content (unlike most instances of humour that are shared within his family) did not bear any relation to his family context, he decided to share it with his family members to emphasise that they should not believe everything that they find online. The humorous (or, more precisely, satirical) nature of this blog post is not immediately obvious, it is tongue-in-cheek; by sharing it, the survey participant intended to show that critical thinking is essential for identifying satirical messages that might at first sight be indistinguishable from serious content. Although such satirical content is neither recent ${ }^{11}$, nor exclusive to online communication, the Internet has become a suitable environment for it to diffuse and thrive (Mocanu et al. 2015: 1198). The popularity of fake news and conspiracy theories on the Internet makes it a milieu where humour and seriousness intertwine in a variety of ways, calling for media literacy and a critical attitude towards information.

Sharing humour in the form of popular Internet-based folklore with one's family members is a handy way to convey ideas that are intended to resonate with the recipient in one way or another and be compatible with their previous experiences, knowledge and views (cf. Cannizzaro 2016: 574). Humour shared within a family has to be appealing to family members' tastes and preferences, engage playfully with their family relations or other aspects

\footnotetext{
8 The video is available at https://www.ok.ru/video/1447788941809 (accessed 18 December 2019)

${ }^{9}$ Original punctuation marks are preserved.

${ }^{10}$ The blog post is available at: https://el-gerund.livejournal.com/272617.html (accessed 18 December 2019)

${ }^{11}$ Cf. Bielefeld Conspiracy, see, for example, here: Granata, 2018, and a whole plethora of similar conspiracy theories about the non-existence of Finland, the Beatles and so on, see Belam, 2017.
} 
of personal biographies, and/or communicate more general values and ideas. As the distinction between humorous and serious modes of communication is often blurry and the boundary between them is situationally determined by interlocutors (Tsakona and Popa 2011: 15; for the interrelation between humour and seriousness, see also Mulkay 1988), sharing humorous folklore within a family can perform a variety of roles, not just entertaining and maintaining relations through phatic communication, but also educating, motivating and commenting on relevant social issues.

\section{The specificities of sharing humour digitally with family audience}

One of the most crucial aspects in sharing humorous folklore (or indeed any information) concerns the audience and its possible reaction. Many of today's online personal media forms of sharing information (such as personal blogs, social media profiles and so on) come close to mass communication forms, as the recipients of the information may be unknown (Lüders 2008: 689). Given the ambiguity of the possible interpretations of folklore - and particularly humorous folklore - creators and sharers of digital humour have to account for multiple factors and employ a certain form of self-censorship while seeking to provoke desired reaction. When sharing humour digitally with one's family members, however, people have a much better understanding of their audience and the forms and topics of humour that can be relevant to them. This implicit knowledge can to some extent compensate for the lack of both immediate conversational context and the nonverbal features found in an oral performance.

Nevertheless, sharing humour within a family may still involve self-censorship, albeit of another kind. Many generic forms of folklore (for example, canned jokes) that circulate within the family are not regarded as impersonal, but are rather adapted to the situation of a particular family and are perceived as potentially referring to family members themselves (for a discussion on this dynamic in cooking jokes, see Fiadotava 2018). Moreover, the oral performance of some of the jokes (and the reaction to them) in family conversations may depend on the interlocutors' mood, health and other temporary factors that are difficult to take into consideration when one is not engaged in face-to-face contact with those with whom they share a joke. In the case of sharing folklore digitally, this means that one has either to try to mitigate the risks of misinterpretation by showing or retelling digital folklore item during a face-to-face interaction in an appropriate moment, or to avoid sharing certain items. A case in point was described by one of my interviewees (female, 33 years old):

There was such a situation recently, we were together with my husband, and my brother was driving us in a car. And something went wrong and we had a quarrel with my brother. And I was flipping through my phone and incidentally found [an image]. Do you remember, there used to be the cartoon "Nu, pogodi!" 12 ? And there was a lion there. And he is sitting, a giant lion with a mane, he is sitting in such a tiny car. At that moment he resembled my brother so much. And I sent this image to my husband, and we were laughing a lot. We were sitting in the same car [...] And afterwards I showed it to my brother, he also laughed.

The practice of sharing humour digitally within a family can also create certain incongruities in itself. Though my data suggest that digital sharing becomes more and more widespread and omnipresent, especially among younger families, there are still certain tensions between technologically-mediated communication and family interactions at home:

Interviewer: Do you also share humour digitally if you are sitting on the nearby sofa? Wife (40 years old): It happens. It makes father [meaning her husband] nervous.

\footnotetext{
12 A popular Soviet and later Russian cartoon, the title is usually translated as "Well, Just You Wait!"
} 
Husband (40 years old): Yes, constantly.

Daughter (15 years old): Father is resenting because you [addressing her mother] are sharing something with me.

Wife: Masha [daughter's pseudonym] and I can keep sending emoji to each other back and forth for 5 minutes, of course it happens very rarely, sharing something cute.

The clash between adherence to oral face-to-face communication and a preference towards digital sharing of humour is just one of the facets of the ever-changing patterns of family interactions. The interference of new media into such an intimate sphere calls for a new way of communicating feelings, providing emotional comfort and support for one's family members. These transformations often involve multidimensional adaptations of generic forms of Internet folklore to the family context.

\section{Conclusion}

Sharing humour digitally with family members is situated on the boundary between the private and public realms. As my data analysis indicates, people tend to choose publicly available humorous media items, but share them privately, reinforcing close personal connections that are maintained offline on a daily basis. This way they have a better control over the information they share and make their messages more targeted (Green et al. 2016: 210). This is especially relevant to the family context, where the specificity of family relations determines certain aspects of digital sharing of humour. Knowing one's audience intimately can be both empowering and intimidating; in contrast to the often impersonal and anonymous sharing of humour across the web, one always has to take into account the fact that the recipients of the humorous message may extrapolate the meaning of even generic forms of folklore to their personal experience and relations. Such a close connection to one's audience allows for more targeted sharing of humour and helps the participants of the interaction to mitigate some of the limitations of digital communication and circumvent the absence of contextualisation cues. In the family context, the effects of digital humorous sharing thus can come closer to the effects of sharing humour orally.

Despite being the focus of this paper, digital sharing cannot be studied in isolation; it is a part of a complex entanglement of interpersonal relations in the family, which are affected by personal values, tastes and preferences of family members, their social and cultural backgrounds, their preferred modes of communication and other factors. Neither can digital sharing be isolated from analogue sharing both on the pragmatic (practices of sharing) and semantic (shared humorous content) levels. Online social networks not only help to maintain offline relations when people are away from each other (Ellison et al. 2007: 1165), but are also actively used in settings where offline communication is also possible. The fact that digital and oral sharing of humour mostly occur among the same pairs or groups of family members also suggests that digital and oral sharing are both parts of the coherent process of humorous communication, which is inspired by the same motivations and guided by the same values.

On a more general level, people's overall attitudes and orientations towards online communication depend to a large extent on family communication environment (Ledbetter 2010: 112). Some families or certain family members might consider digital sharing of humour to be incompatible with conventional family communication patterns, while in other cases it is skilfully integrated into the family's humorous interactions, enriching them and enhancing both the sender's and the receiver's experiences.

The new media and new ways of digital communication have intensified and altered communication practices, but many of them are still "deeply situated in everyday, even mundane creative traditions" (Burgess 2008: 9). These traditions determine the ways, the 
forms and the content of digital sharing. The complex interrelation between the context and the content of humour acquires new dimensions in technologically-mediated communication. Compared to the oral sharing of humour that many of my interviewees and survey participants have experienced since early childhood, the digital way of sharing humour is a relatively new phenomenon in family communication. Regular practices of sharing humour digitally have only become possible following the spread of smartphones and affordable (or even free) wireless Internet. While the practices themselves found their way into family communication rather quickly, the attitudes towards them and the implications of sharing humour digitally in the traditionally face-to-face realm of family interactions are still somewhat unclear and ambiguous, especially among the older generations of some families.

The easiest way to address this issue is to treat digital sharing of humour in the same manner as one would treat an oral communicative event. Many of my research participants have indeed adopted such a perspective, choosing the same topics and applying the same mechanisms of filtering and presenting the information. In this respect sharing humour via instant messengers or on social media while sitting on the same sofa makes perfect sense, as it simply implies choosing a communication channel better adapted to particular content.

However, treating sharing humour digitally in the same way as oral sharing risks undermining the possibilities and challenges opened up by these newer forms of sharing. The distinct temporal and performative dimensions of sharing humour digitally, as well as the preference towards generic visual forms humour (represented by such genres as memes and image macros) as opposed to spontaneous conversational jokes typical of oral communication (Martin 2007: 12), invite critical reflections upon the nature of sharing humour digitally. The asynchronous nature of the digital sharing of humour and the less articulated need for performative skills during such sharing, as well as the eye-catching content of digital humour, makes it more appealing to many (young) families than oral humour. Understanding the digital sharing of humour as a separate phenomenon by no means implies denying the existence of multiple forms that combine the features of oral and digital sharing of humour such as, for example, retelling of online jokes orally, or enjoying online humour together by simultaneously watching it at the same device. Rather, it helps to enhance our awareness of the opportunities and challenges pertaining to various forms of humorous communication within a family.

The present paper has only covered some of the aspects of the digital sharing of humour in family communication. As such, sharing gains more and more popularity, it also requires further, broader investigation. Possible future directions of such investigation include subjecting the data to different methods of analysis, such as the methods of visual analysis and art criticism for the visual humorous examples, narrative analysis for verbal texts, sociolinguistic analysis (see, for example, Hymes 1974), and so on. Another promising way of developing the topic would be to supplement the data with other data sets, for example, collect information from people from a different country/region, and/or use data that does not solely consist of self-reflections and self-reports. This would introduce a comparative dimension to the study of digital sharing of humour and add new layers to our understanding of this complex phenomenon.

\section{Acknowledgements}

This research was supported by the European Union through the European Regional Development Fund (Centre of Excellence in Estonian Studies, TK 145) and is related to the research project "Narrative and belief aspects of folklore studies" (EKM 8-2/20/3, Estonian 
Literary Museum). The author would also like to thank the article's anonymous reviewers for their helpful suggestions.

\section{References}

Andrews, D. K. (2019). 'Kaomoji on the votive tablets of an anime pilgrimage', in Giannoulis, E. \& Wilde, L. R. A. (eds.), Emoticons, Kaomoji, and Emoji: The Transformation of Communication in the Digital Age, London and New York: Routledge, pp. 227-246.

Belam, M. (2017). 'JK Rowling doesn't exist: conspiracy theories the internet can't resist'. The Guardian Available at: https://www.theguardian.com/technology/2017/oct/27/jk-rowlingdoesnt-exist-conspiracy-theories-internet-cant-resist (accessed 18 December 2019).

Blank, T. J. (2012). 'Introduction: Pattern in the virtual folk culture of computer-mediated communication', in Blank, T. J. (ed.) Folk Culture in the Digital Age: The Emergent Dynamics of Human Interaction, Logan: Utah State University Press, pp. 1-24.

Boxman-Shabtai, L. \& Shifman, L. (2015). 'When ethnic humor goes digital'. New Media \& Society 17(4), pp. 520-539.

Burgess, J. E. (2008). 'All your chocolate rain are belong to us?' Viral video, YouTube and the dynamics of participatory culture', in Lovink, G. \& Niederer, S. (eds.) Video Vortex Reader: Responses to YouTube, Amsterdam: Institute of Network Cultures, pp. 101-109. Version available at: http://eprints.qut.edu.au/18431/ (accessed 18 December 2019).

Cannizzaro, S. (2016). 'Internet memes as internet signs: A semiotic view of digital culture'. Sign Systems Studies 44(4), pp. 562-586.

Chen, W., Boase, J. \& Wellman, B. (2002). 'The global villagers: Comparing Internet users and uses around the world', in Wellman, B. \& Haythornthwaite, C. (eds.) The Internet in Everyday Life, Malden, MA: Blackwell, pp. 74-113.

Dingemanse, M. \& Thompson, B. (2019). 'Playful iconicity: triangulating lexical ratings to understand the relation between funniness, iconicity, and structural markedness'. PsyArXiv. Pdf ahead of print 1 October 2019. DOI:10.31234/osf.io/9ak7e.

Dynel, M. (2016). 'I has seen image macros!' Advice animals memes as visual-verbal jokes'. International Journal of Communication 10, pp. 660-688.

E-Belarus.org. (2019). 'Viber leads among messengers in Belarus'. Available at: http://ebelarus.org/news/201909101.html (accessed 18 December 2019).

Edwards, A. P. \& Graham, E. E. (2009). 'The relationship between individuals' definitions of family and implicit personal theories of communication'. Journal of Family Communication 9 (4), pp. 191-208.

Ellison, N. B., Steinfield, C. \& Lampe, C. (2007). 'The benefits of Facebook "friends": Social capital and college students' use of online social network sites'. Journal of ComputerMediated Communication 12, pp. 1143-1168.

Fiadotava, A. (2018). 'Cooking with humour: a study of Belarusian humorous folklore about family cooking traditions'. Folklore. Electronic Journal of Folklore 71, pp. 89-112.

Fiadotava, A. (forthcoming). "If we don't quarrel, we joke": emic perspectives on Belarusian families' humorous folklore'. Humor: International Journal of Humor Research.

Gerhardt, C. (2009). 'Multimodal and intertextual humor in the media reception situation', in Norrick, N. R. \& Chiaro, D. (eds.) Humor in Interaction. Amsterdam/Philadelphia: John Benjamins Publishing Company, pp. 79-100.

Granata, Y. (2018). 'Digital unworld(s): The Bielefeld conspiracy', in Lagerkvist A. (ed.) Digital Existence: Ontology, Ethics and Transcendence in Digital Culture, London: Routledge, pp. 100-114. 
Green, T., Wilhelmsen, T., Wilmots, E., Dodd B. \& Quinn S. (2016). 'Social anxiety, attributes of online communication and self-disclosure across private and public Facebook communication'. Computers in Human Behavior 58, pp. 206-213.

Hymes, D. (1974). Foundations in Sociolinguistics: An Ethnographic Approach. Philadelphia: University of Pennsylvania Press.

Kibby, M. D. (2005). 'Email forwardables: folklore in the age of the internet'. New Media \& Society 7(6), pp. 770-790.

Koerner, A. F. \& Fitzpatrick, M. A. (2002). 'Toward a theory of family communication'. Communication Theory 12(1), pp. 70-91.

Kuipers, G. (2006). Good Humor, Bad Taste: A Sociology of the Joke. Berlin: Mouton de Gruyter.

Laineste, L. \& Voolaid, P. (2016). 'Laughing across borders: Intertextuality of internet memes'. The European Journal of Humour Research 4 (4), pp. 26-49.

Ledbetter, A. M. (2010). 'Family communication patterns and communication competence as predictors of online communication attitude: Evaluating a dual pathway model'. Journal of Family Communication 10(2), pp. 99-115.

Lüders, M. (2008). 'Conceptualizing personal media'. New Media \& Society 10(5), pp. 683702.

Lüders, M., Prøitz, L. \& Rasmussen, T. (2010). 'Emerging personal media genres'. New Media \& Society 12(6), pp. 947-963.

Martin, R. A. (2007). The Psychology of Humor: An Integrative Approach. Burlington: Elsevier.

McKenna, K. Y. A., Green, A. S. \& Gleason, M. E. J. (2002). 'Relationship formation on the Internet: What's the big attraction?'. Journal of Social Issues 58, pp. 659-671.

Medvedeva, I., Kangro, I., Vasilevskaya, Z., Dovnar, O., Kukharevich, Y., Lapkovskaya, T. Palkovskaya, Y. \& Mazayskaya, I. (2019). Belarus' v tsifrakh [Belarus in numbers]. Minsk: Natsional'nyy statisticheskiy komitet Respubliki Belarus'.

Merchant, G. (2007). 'Writing the future in the digital age'. Literacy 41, pp. 118-128.

Mocanu, D., Rossi, L., Zhang, Q., Karsai, M. \& Quattrociocchi, W. (2015). 'Collective attention in the age of (mis)information'. Computers in Human Behavior 51, pp. 11981204.

Mulkay, M. (1988). On humor: Its nature and its place in modern society. Cambridge: Polity Press.

Nevat-Gal, R. (2002). 'Cognitive expressions and humorous phrases in family discourse as reflectors and cultivators of cognition', in Blum-Kulka, S., Snow, C. E. (eds.), Talking to Adults: the Contribution of Multiparty Discourse to Language Acquisition, Mahwah, London: Lawrence Erlbaum Associates, pp. 181-208.

Norrick, N. R. (1993). Conversational joking: Humor in Everyday Talk. Bloomington and Indianapolis: Indiana University Press.

Norrick, N. R. (2003). 'Issues in conversational joking'. Journal of Pragmatics 35(9), pp. 1333-1359.

Nwokah, E. E., Graves, K. N., \& Naylor, J. (2012). 'Family words as creative and affiliative play', in Cohen, L. E. \& Waite-Stupiansky, S. (eds.), Play. A Polyphony of Research, Theories, and Issues, Lanham: University Press of America, pp. 91-118.

Oring, E. (1984). 'Dyadic traditions'. Journal of Folklore Research 21(1), pp. 19-28.

Pettigrew, J. (2009). 'Text messaging and connectedness within close interpersonal relationships. Marriage \& Family Review 45:6-8, pp. 697-716.

Reich, S. M., Subrahmanyam, K. \& Espinoza, G. (2012). 'Friending, IMing, and hanging out face-to-face: Overlap in adolescents' online and offline social networks'. Developmental Psychology 48 (2), pp. 356-368. 
Shifman, L. (2007). 'Humor in the age of digital reproduction: Continuity and change in Internet-based comic texts'. International Journal of Communication 1, pp. 187-209.

Shifman, L. (2014). 'The cultural logic of photo-based meme genres'. Journal of Visual Culture 13(3), pp. 340-358.

Shifman, L. (2014). Memes in Digital Culture. Cambridge, USA: The MIT Press.

Tillman, K. H. \& Nam, C. B. (2008). 'Family structure outcomes of alternative family definitions'. Population Research and Policy Review 27, pp. 367-384.

Tsakona, V. \& Popa, D. E. (2011). 'Humour in politics and the politics of humour: an introduction', in Tsakona, V. \& Popa, D. E. (eds.) Studies in Political Humour: In Between Political Critique and Public Entertainment. Amsterdam/Philadelphia: John Benjamins Publishing Company, pp. 1-30.

Tsakona, V., Giakoumelou, M., Papazachariou, D. \& Archakis, A. (2010). 'The prosodic framing of humour in conversational narratives: Evidence from Greek data'. Journal of Greek Linguistics 10(2), pp. 187-212.

Weng, L., Flammini, A., Vespignani, A. \& Menczer, F. (2012). 'Competition among memes in a world with limited attention'. Scientific Reports 2 (335), pp. 1-8.

Williams, J. (2017). 'World's worst skier' has best explanation: He never trained on snow'. The New York Times. Available at: https://www.nytimes.com/2017/02/24/sports/olympics/adrian-solano-nordic-world-skichampionships.html (accessed 18 December 2019). 